\title{
Resenha Uma teologia para o Evangelho Social
}

\author{
Nelson Lellis Ramos Rodrigues*
}

\section{RAUSCHENBUSCH, Walter. Uma teologia para o Evangelho Social. Vitória: Ed. Unida; São Paulo: Ed. Astes, 2019. 273 p.}

\begin{abstract}
"Um deus teológico que não tem interesse na luta pela justiça e fraternidade não é um Deus cristão."
\end{abstract}

(W. Rauschenbusch)

Em 1918 faleceu o pastor batista Walter Rauschenbusch. Um ano antes publicou, nos EUA, a obra Uma teologia para o Evangelho Social, cuja tradução foi feita por Martin S. Barcala, cientista da religião e pastor metodista. $\mathrm{Na}$ apresentação, os editores Fernando Bortolleto Filho e Wanderley Pereira da Rosa ressaltam o valor da obra para o Brasil, destacando a proposta do autor em relação à superação da ideia do pecado em termos individuais e observando o termo de maneira estrutural/coletiva. Em uma época de polarizações políticas e de profundo envolvimento de evangélicos na esfera pública, o livro auxilia, igualmente, na reflexão acerca da participação de cristãos e seu papel cidadão em países democráticos.

Torna-se aqui desnecessária uma introdução sobre obras e referências bibliográficas utilizadas por Rauschenbusch, uma vez que o teólogo Helmut Renders as fornece com riqueza de detalhes nesta edição. Contudo, há que se destacar que a trajetória do pastor batista fora influenciada pelo embates sociais que vivera na virada dos séculos XX e XXI. Movido por uma leitura das ciências sociais, Rauschenbusch analisou o contexto norte-americano que experimentava o início da modernidade e ganhava fama de potência global

* Doutorando em Sociologia Política pela Universidade Estadual do Norte Fluminense Darcy Ribeiro (UENF). Email: nelsonlellis@gmail.com 
por causa do crescimento nas áreas do comércio e da expansão industrial, com o cinema e a venda de armas de fogo. O avanço do comércio e da indústria permitiu o enriquecimento de grandes magnatas estadunidenses (JUNQUEIRA, 2001), cenário que serviu como alerta no pensamento social e crítico do pastor em tela. Sua teologia sistemática sobre o Reino de Deus baseava-se no compromisso do ser humano com a ordem numa sociedade dominada pelo egoísmo e pela ganância - responsáveis por gerar o caos.

Por outro lado, o clérigo Josiah Strong também foi considerado um dos fundadores do Evangelho Social. Caminhando em sentido oposto ao de Rauschenbusch, Strong entedia que as raças poderiam ser "elevadas" (por crer em raças superiores e inferiores) através da conversão à Cristo. Editor da revista The Gospel of the Kingdom e um dos maiores propagadores do "Destino Manifesto", acreditava que os EUA estavam destinados a estabelecerem o Reino de Deus em todo o mundo, uma vez que o conteúdo deste manifesto entendia que a nação era superior por sua raça branca e por sua fé protestante. O empenho missionário de cristianizar e não civilizar o mundo - como defendeu em seu livro Our Country (1891) -, "alinhado com os ideais do darwinismo social” (JOHNSON, 2017, p. 375), demonstrou características controversas à base do Evangelho Social de Rauschenbusch, que buscava contribuir com um pacto de solidariedade (p. 83) a partir de uma reação profética (p. 63), isto é, de uma experiência religiosa que não poderia ser controlada pela instituição eclesiástica nem pelo senso da desigualdade racial - mensagem que influenciaria um dos maiores expoentes da luta racial no país, o pastor batista Martin Luther King (1960).

A leitura weberiana do pastor Rauschenbusch é um dos principais fatores para a crítica social, onde o sacerdote é visto como "um profissional religioso" (p. 269), que segue à risca a cartilha teológica da tradição institucional, cuja lógica estava dominando artigos, discursos e professores dos seminários responsáveis em preparar novos líderes religiosos (p. 55, 60); enquanto que o profeta "se torna um profeta por causa de alguma experiência com Deus" ( $p$. 270) e, consequentemente, passa a ser responsável por uma mensagem que desafia não só à determinadas teologias, como fizeram, de acordo com sua leitura, "Paulo, Agostinho, Lutero, Fox, Wesley, Schleiermacher" (p. 63), mas também às instituições nacionais que só visam como alternativa "as éticas gananciosas do capitalismo e do militarismo" (p. 67).

Em linhas gerais, considerando seu uso da teoria weberiana, esta edição para o público brasileiro auxilia não só para uma discussão de uma teologia 
sistemática voltada para o que se conhece por "ação social da igreja", mas também acerca do tema que envolve a interface política e religião, uma vez que os evangélicos - que não podem ser vistos como um bloco monolítico - demonstram inclinações ideológicas (partidarizadas ou não) bem distintas (RIBEIRO e LELLIS, 2019). Na liberdade constitucional garantida, tal segmento religioso apresenta teologias que contradizem umas às outras com o objetivo de defenderem seus posicionamentos político-sociais (assim como grupos que acompanhavam os ensinos de Strong e os de Rauschenbusch). O Evangelho Social de Rauschenbusch defende que não é possível haver ordem social sem atores ligados ao evangelho (p. 203). Neste aspecto, qual evangelho é possível associar à mudança social e política? Em que sentido esta edição contribui para a discussão do papel da igreja no Brasil?

Um evangelho cujo "interesse permanece na terra" (p. 73) para lutar contra o pecado do egoísmo, que instila a desigualdade social. O pecado é revelado em contraste com a justiça (p. 89). É necessário, portanto, para o pastor batista, renovar a visão do Reino de Deus a fim de: combater lobbies que buscam eliminar legislações e que regulam a cumulação de propriedade; combater a guerra, cujo interesse é lucrar sobre países empobrecidos; combater interesses privados, que desequilibram a balança comercial resultando em desigualdade social (p. 92). E não é possível, em sua teologia, um envolvimento da igreja nesta escala sem engajamento/manifestação social.

A fim de compreender tais manifestações sociais a partir de um viés teológico sistemático, lanço mão da teoria do protesto em James M. Jasper (2016). O sociólogo estadunidense entende que toda a manifestação de protesto nasce da cultura onde o indivíduo está inserido. Isso parece óbvio, mas para destacar a construção de um ator que protesta contra determinado status quo, como Rauschenbusch, não resta outro caminho a não ser pelas categorias norteadas pela cultura. São elas: a) a cognição; b) as emoções; c) a moral. Aliadas não apenas ao aspecto da cultura nacional (macro), mas sobretudo a cultura religiosa (micro[s]), analisaremos a crítica da teologia sistemática do pastor batista e o que dela se pode destacar para o atual cenário brasileiro.

Em relação à cognição, Jasper entende que as palavras utilizadas contra injustiça social são retiradas de um conteúdo de crenças (religiosas ou não) sobre o mundo. Palavras afirmam o que o mundo é, suas distinções entre uma coisa e outra, entre um grupo e outro. Elas classificam. Neste aspecto, há o que Jasper chama de "teoria de vítimas" e "teoria dos vilões". Essas narrativas são construídas como parte da cognição. 
Dentro da cultura religiosa dos EUA, o exercício praticado por Rauschenbusch, que também era professor de História da Igreja no Seminário de Rochestes, em Nova Iorque, era de criticar o capitalismo e o ensino teológico praticados como construção de uma narrativa social e que se ausentava do combate às injustiças sociais. Em sua concepção, só o Evangelho Social seria capaz de "despertar a consciência social da nação para o perigo de permitir que tais forças [suprapessoais do mall se tornem opressoras e parasitárias" (p. 110).

Embora tivesse simpatia pelo "instinto conservador", Rauschenbusch considerava, metaforicamente, o ensino de seminários conservadores de sua época como o aquele que "para o relógio" (ou "parado no tempo") e/ou que guarda "doutrinas sobre a prateleira" a fim de que nenhuma criança possa alcançar (p. 55). Este foi o sentimento de teólogos brasileiros no período da ditadura militar, tais como: João Dias de Araújo (2010), Zwínglio Mota Dias (2017), Joaquim Beato, Anivaldo Padilha, Rubem Alves. Ao olharem para os seminários de suas igrejas na década de 1960 e testemunharem professores e alunos expulsos por não concordarem com uma leitura bíblica que não dialogava com a sociedade, buscaram aplicar uma visão do Reino de Deus onde pudessem lutar por melhores condições sociais e não apenas pregarem a "salvação das almas" (BITTENCOURT FILHO, 2014; SOUZA, 2014). Rubem Alves (p. 16) chegou a declarar que Rauschenbusch seria uma espécie de precursor da Teologia da Libertação, uma vez que o seu movimento, sendo criticado pela teologia conservadora, ligava fortemente o evangelho a grupos semelhantes àqueles para os quais Jesus se inclinava: oprimidos, pecadores, injustiçados. E na atual conjuntura, percebe-se diferentes teologias (negra, feminista, queer) buscando exercer seu papel à luz de uma sociedade plural, mas também desigual (SOUZA, 2017), mesmo encontrando barreiras em seminários que Rauschenbusch continuaria identificando como aqueles "parados no tempo".

Uma característica que salta aos olhos quanto à escolha por um evangelho que dialogue com a sociedade é a leitura de determinados textos. Rauschenbusch fora influenciado por autores como o já citado Max Weber, Albrecht Rischl, Richard Rothe, Friedrich Schleiermacher, chamando-os, inclusive, de profetas - mesmo criticando o método individualista deste último. As ciências sociais também fizeram parte na década de 1960 entre os evangélicos chamados progressistas. Em 1962, na cidade de Recife, houve a "Conferência do Nordeste: Cristo e o processo revolucionário brasileiro", 
onde havia um grande interesse em colocar a teologia em diálogo com as ciências sociais. Convidaram, portanto, intelectuais e sociólogos para o evento. Estiveram presentes nomes como Gilberto Freyre e Celso Furtado. "A ideia era trabalhar numa direção de uma teologia pública e cidadã, com iniciativas políticas inclusivas, preocupadas com as minorias e, consequentemente, antenada com as condições sócio-políticas da época" (LELLIS, 2019, p. 87). O cenário pós-impeachment da presidente Dilma Rousseff, atenuou a presença do conservadorismo religioso no Brasil (ALMEIDA e TONIOL, 2018; PY, 2018) e muitos evangélicos, com formações diversas, demonstram interesse semelhante ao de Rauschenbusch quanto ao Evangelho Social (RIBEIRO e LELLIS, 2019).

As emoções são um outro aspecto norteado pela cultura. Para Jasper, as emoções ajudam a manter indivíduos "mais próximos das vidas reais das pessoas" (JASPER, 2016, p. 26). Emoções e sentimentos ajudam a formular métodos de ação, além de serem funcionais e perspicazes. As emoções dão vida às narrativas e "fazem com que nos preocupemos com identidades coletivas, ajudam-nos a odiar vilões ou a ter piedade das vítimas" (JASPER, 2016, p. 27). Neste sentido, é possível entender porquê Rauschenbusch, influenciado por Schleiermacher, não descarta as experiências que acredita atualizarem a visão do Reino de Deus na sociedade. Para isso, apela para o sentimento dos profetas do Primeiro Testamento e das narrativas sobre o Cristo. A compaixão que tiveram para com os menos favorecidos e a denúncia destemida diante do caos social provocado por determinadas instituições e grupos elitizados.

Os cristãos, segundo o Evangelho Social, têm a tarefa de interpretarem profeticamente os tempos e viverem com a mesma compaixão dos exemplos retirados das escolas proféticas (p. 63). A teologia individualista que vigorava nos EUA fazia com que este pastor desse crédito ao menos aos hinos cantados como forma de combatê-la. No Brasil, o mercado fonográfico gospel acompanha a teologia pregada na maioria das igrejas evangélicas (CUNHA, 2007), o que não ajudaria - como ocorreu no início do séc. XX - como ferramenta crítica para o fomento de emoções a fim de capacitar o fiel ao exercício profético na comunidade.

Por fim, o componente da moral. Jasper separa tal aspecto em duas partes. A primeira, como um conjunto de princípios explícitos, utilizando, inclusive, a regra de ouro evangélica: "Fazei aos outros o que quereis que vos façam". Neste caso, a finalidade é persuadir doutrinariamente outras 
pessoas com determinado ponto de vista. Esta regra é amplamente utilizada por Rauschenbusch em seu Evangelho Social, pois condena os "parasitas" que caminham para a "perdição física, intelectual e moral" (p. 93). A segunda parte, são as intuições morais não formuladas. Elas são sentidas rapidamente e ajudam "a pensar, inclusive sobre o que é certo e errado" (JASPER, 2016, p. 27). Rauschenbusch entendia que essa intuição poderia ser absorvida pelo ensino equivocado das instituições e não permitir que fosse utilizada para o bem da sociedade (p. 98) - algo que P. Bourdieu (1974) destacaria à frente com seu conceito de habitus.

No Brasil de hoje, as discussões sobre engajamento cívico/político, à luz do primeiro conceito de moral, e das intuições que vão além dos manuais de teologia, parecem abrir espaço cada vez mais para problematização da identidade de um evangelho que dê respostas concretas a este mundo. Comunidades, coletivos, grupos evangélicos que dissociam-se de instituições com CNPJ e crescem cada vez mais em número para uma participação na sociedade - que entendem - como mais coerente com o Evangelho (RIBEIRO e LELLIS, 2019). A atividade, o fazer algo para além de "salvar as almas", parece retomar com a mesma potência que as redes sociais, por exemplo. Tais redes servem como ferramenta de circulação de notícias verdadeiras e falsas para o fazer político, legitimadas pela bíblia e a interpretação que se quer para ela.

O tempo dirá como a obra Uma teologia para o Evangelho Social, que é uma teologia sistemática (ou seja, que não invalida o pensamento confessional), será discutida (e se será) em determinados seminários e faculdades de teologia no Brasil e como as instituições (re)organizarão suas ações a partir de reflexões como estas. Até porque, outros temas (res)surgem para o debate, como a descriminalização do aborto, legislação sobre armas de fogo, diminuição da maioridade penal, direitos da comunidade LGBTQ+, meio ambiente, direitos humanos e tantos mais que a igreja, feita de cidadãos e cidadãs, terá a sua escolha mediada pelo evangelho que quiser seguir.

\section{Referências}

ALMEIDA, Ronaldo de; TONIOL, Rodrigo (orgs.). Conservadorismos, fascismos e fundamentalismos: análises conjunturais. Campinas-SP: Editora da UNICAMP, 2018.

ARAÚJO, João Dias de. Inquisição sem fogueiras: a história sombria da Igreja Presbiteriana do Brasil. São Paulo: Fonte Editorial, 2010. 
BITTENCOURT FILHO, José. Caminhos do protestantismo militante: ISAL e Conferência do Nordeste. Vitória: Ed. Unida, 2014.

BOURDIEU, Pierre. A economia das trocas simbólicas. São Paulo: Ed. Perspectiva, 1974.

CUNHA, Magali do Nascimento. Explosão gospel: um olhar das ciências humanas sobre o cenário evangélico no Brasil. Rio de Janeiro: Mauad X; Instituto Mysterium, 2007.

DIAS, Zwínglio Mota. A reinvenção do protestantismo reformado no Brasil. São Paulo: Fonte Editorial, 2017.

JOHNSON, J. A. (org.). Reforming America: A Thematic Encyclopedia and Document Collection of the Progressive Era. Santa Barbara: ABC-CLIO, 2017.

JUNQUEIRA, M. A. Estados Unidos: a consolidação da nação. São Paulo: Contexto, 2001. KING JR., Martin Luther. "Pilgrimage to nonviolence". Christian, New York, 1960, p. 439-447.

LELLIS, Nelson. "Como se articula o golpe pela via (dolorosa) da religião?”. In: PINEL, Hiran; LELLIS, Nelson. Religião, educação e política. São Paulo: Ed. Recriar, 2019, p 85-92.

PY, Fábio. "Curitiba: capital do ultraconservadorismo religioso batista”. In: PY, F.; LELLIS, Nelson (orgs.). Religião e política à brasileira: ensaios, interpretações e resistência no país da política e da religião. São Paulo: Ed. Recriar, 2018.

RIBEIRO, Cláudio de Oliveira; LELLIS, Nelson (orgs.). Religião \& política à brasileira: faces evangélicas no cenário religioso. São Paulo: Ed. Recriar, 2019.

SOUZA, Jessé. A elite do atraso: da escravidão à lava-jato. Rio de Janeiro: Leya, 2017.

SOUZA, Silas Luiz de. Protestantismo \& Ditadura: os presbiterianos e o governo militar (1964-1985). São Paulo: Fonte Editorial, 2014.

STRONG, J. Our Country: Its Possible Future and its Present Crisis. New York: Baker and Taylor Company, 1891. 